\title{
Some provinces still delay access to health records via patient portals
}

\author{
n Cite as: CMAJ 2019 December 2;191:E1341. doi: 10.1503/cmaj.1095829
}

Posted on cmajnews.com on November 12, 2019

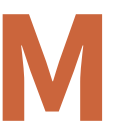

ost provinces now provide patients online access to some of their health records. But there is still variation in the type and timing of information released through these portals.

Saskatchewan is the latest province to launch a patient portal. Residents can use MySaskHealthRecord to view their lab results, medical imaging reports and clinical visit history, including hospital admissions. What's more, they can see the information as soon as it becomes available $-a$ first in Canada.

Other provinces delay the release of health information through patient portals by days or weeks. In Quebec, for example, patients must wait 30 days after an ordering physician receives their test results to access those results through the province's Carnet Santé or Health Booklet portal. Doctors in the province requested the delay to ensure they have enough time to arrange appointments with patients who have abnormal findings.

Dr. Dennis Desai of the Canadian Medical Protective Association says that unfettered access to information can be damaging, depending on the patient and the nature of the information. He likens it to receiving a technical report about your car without any context.

"Imagine you go to your car mechanic and you just get a report that says your brake pads are at five millimeters and your brake fluid is $20 \%$ contaminated. Is that an issue? Is it safe to drive away? You can't just put that report on me on Friday night, then leave me with that until Monday, when I can phone you," Desai says.

Desai argues that the degree of access to information should be based on what's best for patients. But who gets to decide what's best for patients?

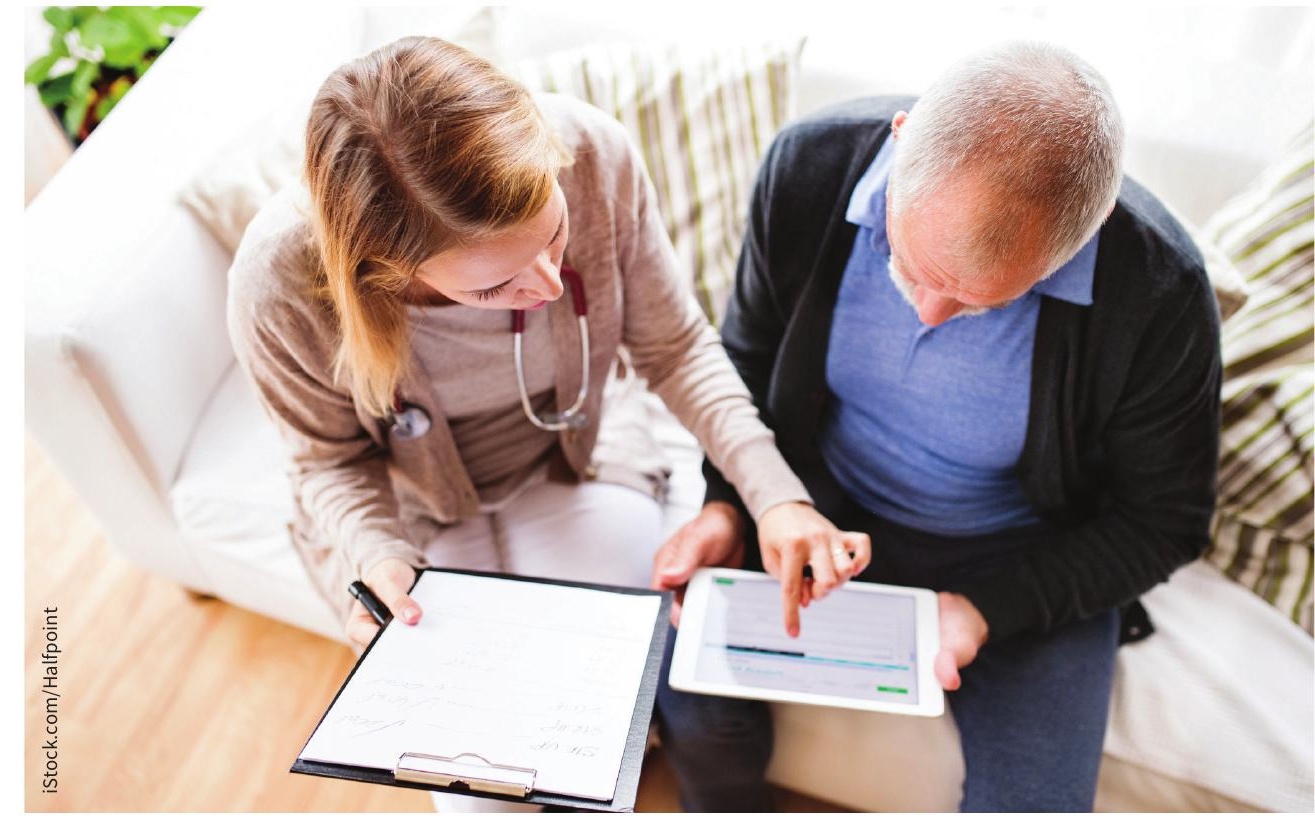

Depending on where you live in Canada, it can take days or weeks for test results to show up in your online health record.

Nova Scotia leaves it up to individual family doctors to decide when results are released to their patients but recommends a five-day delay for test results that would benefit from "interpretation by the ordering provider."

Alberta, meanwhile, only makes some lab test results available, as selected by physicians and public advisory groups, with an eye to striking a balance between immediate access to the most common tests and keeping doctors as the main point of contact for tests that could show a critical diagnosis.

However, patients take a different view of the matter. Nine out of 10 Canadians believe they should have full ownership of their health data and 95\% believe they should be the ones approving who gets access, according to a national survey conducted by the Canadian Medical Association. Three in four Canadians also said they expect to have access to their complete medical history and the ability to share that information as they see fit within the next decade.

Michael Green, president and CEO of Canada Health Infoway, says Canada is still working through a cultural shift away from a model where access to health information is controlled by doctors, hospitals and governments, to a model where patients own their own data.

"Most people are coming around to the fact that the blockbuster drug of the 21st century is a fully informed patient," says Green. "If patients are already informed about a result when they go to see the doctor, they can come prepared with questions and take more interest in finding out about the result."

Greg Basky, Saskatoon, Sask. 